\title{
El Cine de animación, transmisor de marcas y valores culturales
}

\author{
Anna Amorós Pons \\ Universidad de Vigo - España \\ amoros@uvigo.es \\ Patricia Comesaña Comesaña \\ Adquiero Servicios Integrales de Formación - (Vigo) \\ print13@hotmail.com
}

\section{Resumen}

El artículo forma parte de una investigación integral sobre la imagen cinematográfica como soporte publicitario. Se estudia las modalidades de inserción publicitaria en el cine de animación por ser el preferido, como opción de entretenimiento, por diferentes públicos. Los resultados ponen de manifiesto que el cine de animación es una interesante plataforma para analizar las estrategias publicitarias utilizadas por empresas e instituciones para difundir mensajes e ideologemas. La publicidad encubierta es la más recurrente, donde el brand placement es el que alcanza mayor presencia.

Palabras clave: Cine de Animación, Inserción Publicitaria, Cultura, Ideologemas

\section{The animation movies, transmitter of brands and cultural values}

\begin{abstract}
This article is part of a comprehensive research on the film image as an advertising medium. We study the advertising insertion on animation cinema for being preferred for several audiencies as entertainment option. The results prove that animated film is an interesting platform to analyze the advertising strategies used by companies and institutions to disseminate messages and ideologemes. Concealed advertising is the most frequent, where the brand placement is reaching greater presence.
\end{abstract}

Key words: Animation Movies, Advertising Placing, Culture, Ideologemes

\section{Referencia normalizada:}

Amorós Pons, A.; Comesaña Comesaña, P. (2013) El Cine de animación, transmisor de marcas y valores culturales. Historia y Comunicación Social. Vol. 18 Nºspecial Noviembre. Págs. 75-85.

Sumario: 1. Introducción. 2. Metodología de la investigación. 3. El estudio y sus resultados. 4. Conclusiones y Tendencias. 5. Referencias bibliográficas. 6. Notas.

\section{Introducción}

A mitad de la década de los 90 el cine de animación, como oferta de entretenimiento en diversos medios, soportes y pantallas, se convirtió en uno de los principales productos de consumo audiovisual (Cartoon Forum) para distintos públicos. Esto 
conlleva que empresas y agencias de publicidad se interesen por las posibilidades que oferta la imagen cinematográfica como soporte publicitario.

A partir de las aportaciones teórico-metodológicas de los pioneros, con diversos estudios sobre el tema en estas dos últimas décadas y desde distintos ámbitos, sobre la inserción de mensajes comerciales a través de la tipología product placement (Vollmers y Mizerski, 1994; Babin y Carder, 1996; Law y Braun, 2000; Baños y Rodríguez, 2003; Del Pino y Olivares, 2007), o bien sobre el uso publicitario de la imagen cinematográfica realizada con imagen real (Solomon y Englis, 1994; Antonopoulou, 2010; Salazar y Lau Chufon, 2010; Walton, 2010), o su utilización en series y programas de televisión (Méndiz, 2007; Martínez, 2008; Segarra y Plaza, 2012), así como en videojuegos (Selva, 2009; Amorós, 2009; Farias, 2012) y en telefonía y dispositivos móviles (Adelantado \& Martí, 2012), hay que indicar que no se ha puesto mucho hincapié en el desarrollo de investigaciones que centre su objeto de estudio en la utilización de las distintas tipologías de publicidad no tradicional (como los créditos y el brand placement) que utilizan los filmes de animación como soporte para vehicular productos, marcas y valores socio-culturales que transmiten la idiosincrasia de un pueblo o sociedad concreta (Amorós y Comesaña, 2012), o bien estudios que abarquen la relación tan específica existente entre Cine de animación-Publicidad-Educación-Consumo.

Partiendo de esta realidad, cuando se analiza el cine de animación como soporte publicitario -a partir de los postulados de un amplio abanico de autores que abordan desde distintos enfoques el tema de las relaciones Cine y Publicidad (Pérez, 1996; Redondo, 2000; Baños y Rodríguez, 2005; Perales et al., 2007; Amorós, 1999 y 2012)- hay que tener en cuenta una serie de consideraciones.

La primera es que este cine convierte al espectador infantil en un consumidor activo (Propper, 2007: 29), en un potencial comprador al ser prescriptor de la compra familiar. En segundo lugar, tampoco se puede reducir sólo al grupo infantil el público de este tipo de cine porque es limitar sus posibilidades comunicacionales-publicitarias, al ser un producto audiovisual que abarca, en su consumo, segmentos de públicos distintos (Pereira, 2005:42). La tercera, está en que este cine influye de manera determinante en los patrones de comportamiento, socialización y consumos (Bringué, 2001:107), despertando el interés generalizado, tanto entre los especialistas de los procesos de recepción y efectos en los niños de los mensajes persuasivos insertados (Del Moral, 1999; Montoya, 2007; Vollmers y Mizerski, 1994; Walton, 2010) como en los estudiosos de las nuevas estrategias de los anunciantes para llegar al público objetivo de una manera velada que se aleja de los tradicionales canales publicitarios (Amorós y Martínez, 2000; Comesaña, 2010). Una cuarta consideración a tener en cuenta en este mundo de consumo globalizado es que este cine provoca, en una edad aún temprana en cuanto a formación y madurez cognitiva, una homogenización (Pereira, 2005; Zapater et al., 2004) de estilos, preferencias, comportamientos y valores socio-culturales, que ya no son dictados por el entorno educador directo (padres, familia, profesores). Y, finalmente, hay que considerar la ausencia de límites entre lo que se considera y es realmente una imagen cinematográfica y una imagen publicita- 
ria; pues, es aquí donde la comunicación publicitaria establece su complejidad entorno a nuevas tipologías "no tradicionales" insertadas sutilmente en medios y soportes que originariamente no se crearon para difundir dichos mensajes persuasivos y comerciales (Perales et al., 2007:81). Las relaciones entre Cine y Publicidad se remontan a los propios orígenes de la imagen animada (Amorós y Martínez, 2000:113), desde sus comienzos muchos directores utilizaron el Séptimo Arte para difundir, explicita o implícitamente, mensajes (comerciales) y promover valores (socio-culturales), una imagen cinematográfica utilizada como soporte promocional-publicitario comercial, turístico, político-propagandístico (Amorós, 1999:123ss).

\section{Metodológia de la investigación}

El artículo resume los principales resultados de un estudio enmarcado dentro de un proyecto más global (ref. 64102N001 y 64102N801) sobre la imagen cinematográfica como soporte publicitario, dentro de la línea de investigación de las relaciones Cine y Publicidad (Grupo I+D CS2). En el año 2010 se pone en marcha en la Universidad de Vigo el Proyecto AUGAL ${ }^{1}$, que nos permite activar esta línea de trabajo en el ámbito específico del cine de animación en el Siglo XXI, partiendo de la hipótesis de que este utiliza intencionadamente la imagen cinematográfica como soporte de diversas modalidades publicitarias, en las que se transmite marcas, productos comerciales pero también valores socio-culturales.

Metodológicamente se opta por un estudio de tipo histórico-descriptivo-analítico, cualitativo y cuantitativo. La muestra de análisis comprende más de ciento veinticinco películas de animación producidas en esta década, lo que nos condicionó por su amplitud a realizar una catalogación atendiendo a distintos parámetros (procedencia geográfica de la producción, políticas empresariales, etc.) y a los diferentes estilos creativos (animé, 2D, 3D, stop-motion, pixilación, etc.). De este modo, el panorama de la producción de cine de animación quedaba delimitado a cinco áreas geográficas (Norteamérica, Asía, Europa, Estado español y Galicia).

Para obtener datos más específicos se concretó una muestra más reducida para un análisis detallado. En esta fase, se establecieron cinco modelos que se concretan en cinco películas claves según la referencia geográfica: en Estados Unidos, The Wild (C.O.R.E. Feature Animation y Walt Disney Pictures, 2006); en Japón, El viaje de Chihiro (Studio Ghibli, 2001); en Europa, Wallace \& Gromit: la maldición de las verduras (Aardman Animations y DreamWorks Animation, 2005); en España, Gisaku (Filmax, 2005); y, en Galicia, El Bosque Animado (Dygra, 2001). Para la recogida de datos y su sistematización, se elaboraron Tablas de Inserción Publicitaria (las TIP) que contemplan distintas variables observables y una relación de categorías: Tabla Identificativa de Producción, Modalidad Publicitaria, Inserción Publicitaria, Transmisión Patrimonial y Valores.

Con el análisis se manifiesta la presencia de diversas tipologías publicitarias que recurren al cine de animación para diseñar estrategias de persuasión e insertar mensa- 
jes, para difundir de forma masiva reclamos publicitarios que inciten al público al consumo de dichas marcas y productos. Pero también se constata la existencia de mensajes de promoción del patrimonio histórico-cultural (promovidos por Administraciones) y aquellos mensajes insertados en el relato (en el propio guión) que aluden a valores socio-culturales.

Por motivo de acotación de espacio y tiempo en el texto, se dan a conocer los resultados de las modalidades de inserción publicitaria más características en el ámbito de la publicidad indirecta (mecenazgo y patrocinio) y, en el ámbito de la publicidad encubierta, la más velada por su carácter fugaz en la imagen (los créditos del printer) y la más perniciosa por su sutileza (la ficción publicitaria en el relato), al estar reforzada la ficcionalidad por el carácter animado de la imagen. Se aporta información relevante de esta actividad mercantil e ideológica con el fin de que se puedan planificar y tomar medidas de actuación en la esfera social (a nivel legislativo, publicitario, educativo, familiar) sobre estas prácticas publicitarias encubiertas en el cine de animación de este milenio.

\section{El estudio y sus resultados}

Aunque el estudio lo centramos en un tipo de imagen que se anima (Laboure, 1998:12; Sánchez-Escalonilla, 2003: 28; Konigsberg, 2004:161; Taylor, 2004:7; Magny, 2005:33; Wright, 2005:1; Selby, 2009:6), se evidencia en el análisis que este cine recurre a las misma estrategias publicitarias que el de imagen real. Pero, al mismo tiempo se constatan que son estrategias novedosas, en el sentido expuesto por Kleppner's (Benavides, 2003:186), si se comparan con la publicidad de los mass media tradicionales.

En el estudio, el concepto de publicidad (con sus múltiples acepciones según Aguilar, 1975: 87; Arens, 2000:7; Baños, 2001:133; Bassat, 1994:13; Benavides, 2003; Dahdá, 2005: 19; Eguizábal, 2007: 31; Ferrer, 1980: 102; Figueroa, 1999: 22; García, 2001: 21; González, 1996: 57; Kleppner, 1988: 27; Kotler, 1995: 654; Ogilvy, 1989: 7; Ortega, 1997: 21; Perales, 2007:81), se enfoca desde el punto de vista de la publicidad generada a través de la imagen cinematográfica (Amorós y Comesaña, 2012: 96). Teniendo presente este postulado nos acercarnos a las distintas modalidades de inserción (indirectas y encubiertas) que nos ayudarán a entender cómo se llevan a cabo las acciones publicitarias en el cine de animación. En primer lugar, se analizaron el mecenazgo y patrocinio (Parés i Maicas, 1991; Ortega, 1997; Redondo, 2000; Gutiérrez, 2002), donde su uso genera una relación de colaboración beneficiosa tanto para la productora como para la entidad patrocinadora o mecenas. Los resultados diferenciaron su empleo según el origen de la producción. Constatamos que la japonesa y estadounidense disponen de capacidad de autofinanciación, por lo que no necesitan apoyos económicos, ya que sus éxitos de taquilla son suficiente aval para arrastrar espectadores a las salas de cine. En el lado opuesto, las producciones europeas se ven obligadas a recurrir a estas formas de publicidad para conseguir ingresos y financiar 
la producción. En concreto, la producción española y gallega buscan colaboradores y financiación a través de entidades privadas y/o públicas, subvenciones e iniciativas creativas (crowdfunding). La gallega es la que más recurre a ambas tipologías indirectas (patrocinio de Antena 3, Megatrix, Vía Digital y el mecenazgo de Televisión de Galicia, Xunta de Galicia o el Programa Media), mientras que la española acude exclusivamente al mecenazgo por la concepción de producto promocional que es Gisaku. Instituciones como Xunta de Galicia, Instituto Galego de Promoción Económica, Turespaña participan como mecenas. En cuanto a su presencia, se realiza insertando logotipos corporativos de empresas/instituciones financiadoras/colaboradoras bajo el modelo de ayuda ("patrocinado por", "en colaboración", "con el apoyo") en los créditos.

Esta modalidad encubierta hace referencia a la aparición de marcas y agradecimientos en el printer con formato de texto plano o logotipos (Taylor, 2004). A pesar de ser la modalidad más numerosa, en términos publicitarios cantidad e impacto no son proporcionales pues, no se presentan como una estrategia de gran relevancia debido a su naturaleza (ubicación en printer con diseño poco atractivo, con texto tipográfico reducido, de proyección rápida, lo que impide su lectura y donde muchos espectadores abandonan la sala). El estudio constata que los créditos son una tipología muy abundante, especialmente en la producción gallega y española donde alcanzan la mitad de las inserciones del estudio comparativo. La razón es que las producciones de aquí necesitan más ayuda, lo que les hace depender de apoyos institucionales y subvenciones. En la cinematografía gallega y española, se constata la presencia de instituciones de ámbito autonómico y nacional (Museo de Arte Contemporánea de Andalucía, Organismo Autonómico de Parques Nacionales), de empresas y entidades públicas o privadas (AGAPI, Animadrid, Cines Los Rosales) y marcas comerciales (Kodak, Bocatta, Ford, F.C. Barcelona). Frente a estas, la industria estadounidense y japonesa se caracterizan por insertar marcas de grandes multinacionales. En The Wild encontramos Capitol Records, EMI Film \& Television Music, Walt Disney Records, Kodak; y en el caso nipón referencias a estudios profesionales como Anime Toro Toro, Oburo Dakushon, Sutajio Kokupitto.

En cuanto a la publicidad encubierta del brand placement (Méndiz, 2007; Amorós y Comesaña, 2012), la modalidad más velada en el cine, la encontramos en el propio relato o formando parte del guión cinematográfico. Esta inserción que, obtiene gran notoriedad al no pasar desapercibida para el espectador, se realiza de tres modos. Mencionando explícitamente el nombre de una marca (Real Madrid, Copa de América de Vela, AVE, Ternera Gallega) caso del modelo gallego y español, o citando variedades de queso en la película europea. El otro es alabando las cualidades de la marca acompañada de la presencia física del producto o logotipo reforzando su poder persuasivo (en la producción nipona se referencia la seguridad y robustez del coche Audi de la familia). Y, el tercero, consumiendo el producto que se anuncia. La española Gisaku es el ejemplo de explotación de la ficción publicitaria con carácter institucional. En la película estadounidense no se aprecia la ficción publicitaria, debido a que se decanta por estrategias de emplazamiento de productos. 
Finalmente, la imagen cinematográfica animada se utiliza como soporte para la transmisión de valores culturales, sociales y patrimoniales que forman parte de la construcción del imaginario social (Amorós, 1996; Hueso, 1998; Camarero Izquierdo y Garrido Samaniego, 2004; Fernández, 2005) de modo que las películas se convierten en herramientas de seducción, modelaje de conductas, socialización infantil o como documento histórico del mundo contemporáneo.

La publicidad recurre al cine de animación como soporte publicitario para atraer turistas, potenciar la imagen de un país con elementos de referencia de identidad cultural y etnográfica (gastronomía, folclore, paisaje, arquitectura, historia, patrimonio, etc.). Se entiende que el cine genera en el imaginario de los espectadores paraísos bucólicos que atraen la atención y el interés por visitarlos y conocerlos. Para contribuir a esta potenciación turística, las Films Commissions juegan un papel primordial en facilitar los rodajes de largometrajes, documentar y asesorar a los creadores de animación para recrear los escenarios reales, etc. Así Gisaku se concibió como soporte promocional de la Marca España, con el objetivo de atraer al visitante nipón, un turista que hubiese sido indiferente al reclamo publicitario comercial tradicional de sol y playa. Se presentan elementos culturales y etnográficos como el Parque Güell, La Sagrada Familia o el IV Centenario Don Quijote de la Mancha,... ciudades como Bilbao, A Coruña, Sevilla, Madrid, Valencia o Barcelona. Por su parte, El bosque animado transmite imágenes del patrimonio cultural y natural gallego (hórreos, paisajes rurales,...) para despertar el interés por Galicia (Comesaña, 2008). Wallace \& Gromit sirve de aproximación a la idiosincrasia del pueblo británico, donde personajes y decorados transmiten características culturales y costumbres anglosajonas (la hora del té), del paisaje y arquitectura (casas señoriales inglesas y de estilo victoriano), del humor británico de corte serio que busca el absurdo. The Wild trasmite rasgos de cultura estadounidense con valores como la libertad, el consumismo, la pertenecía al grupo social, la amistad o la hegemonía americana. Y El viaje de Chihiro nace de la especial concepción del director al tratar de transmitir veladamente mensajes para que el espectador reflexione sobre la sociedad nipona contemporánea que, para Miyazaki, ha perdido el honor, el respeto por las tradiciones y la religión.

\section{Conclusiones y tendencias}

Partiendo de la premisa de que la utilización del cine de animación como soporte promocional es un campo poco tratado, el estudio arroja datos significativos en relación al uso de diversas tipologías que se sirven de la imagen para llevar a cabo acciones de publicidad indirecta (mecenazgo y patrocinio) o encubierta (brand placement y créditos). Estos modelos confirman su capacidad para difundir de forma masiva mensajes de carácter comercial a un público infantil y adulto con la finalidad de inducir a la compra de bienes de consumo (Perales, 2007:129), pero también la capacidad de educar o transmitir valores sociales. 
Se ha constatado que el cine de animación de este milenio sigue el modelo de financiación a través de la inserción publicitaria ya consolidado en otros medios como la televisión, el cine de imagen real o la radio. Esta técnica se presenta altamente rentable, para la productora y para el anunciante, en términos económicos y comunicación. Las modalidades indirectas se convierten en modelos de financiación de las producciones europeas, españolas y gallegas. Respecto a las encubiertas, la ficción publicitaria se constata como un recurso de gran impacto en cualquier producción, mientras que los créditos a pesar de ser muy abundantes no alcanzan gran notoriedad por lo que se tenderá hacia la creación de diseños más atractivos (interacción de los personajes animados con el printer; inclusión de escenas animadas generadas para los créditos; tomas falsas; imágenes del making of o de autopromoción que acompañan al printer).

Al relacionar el cine de animación con la promoción de valores se constata su capacidad para transmitir mensajes comerciales y socio-culturales. Este poder persuasivo para vehicular marcas e ideologemas favorecerá la creación de producciones que respondan a intereses de empresas, entidades o marcas comerciales, introduciendo mensajes comerciales desde la fase de guionización hasta nuevas fórmulas publicitarias interactivas y multisoporte que vinculen diferentes medios. Las referencias para la construcción de los relatos cinematográficos favorecen la adecuación del producto/ marca a la historia filmica donde las productoras explotarán publicitariamente estas producciones buscando rentabilizar el producto cinematográfico (videojuegos, redes sociales, spin off, apps) y abriendo un mundo de posibilidades a nivel profesional.

Este uso pernicioso y velado del cine de animación debe ser atendido por la comunidad educativa para conocer este uso secundario de los productos de ocio infantil. Estas estrategias persuasivas se expanden hacia otros soportes, tejiendo una red que busca inducir a los menores en el consumo de bienes, productos y servicios. De este modo llegan a su público objetivo de una manera sutil que se aleja de los tradicionales canales publicitarios, que aún empleando las mismas técnicas, su efectividad es muy alta ya que se encuentra ante un espectador vulnerable, por edad y formación. Por estas razones, docentes y padres deben inculcar una visión crítica en los menores de modo que sean conscientes de esta estrategia para modelar conductas en el público.

\section{Referencias bibliográficas}

\section{Bibliografía}

ADELANTADO MATEU, E.; MARTÍ PARREÑO, J. (2012). "Nuevos formatos publicitarios y telefonía móvil: los mobile advergames". En: Zer, Vol.17, n 33, Bilbao: Servicio Editorial Universidad País Vasco. p. 31-45.

AGUILAR ÁlVAREZ DEL ALBA, A. (1975). Elementos de la mercadotecnia. México: Cecsa.

AMADO DE ANDRÉS, A. (1993). Mecenazgo \& patrocinio. Las claves del marketing del siglo XXI. Madrid: Editorial Editmex. 
AMORÓS PONS, A. (1996) "A Galicia dos contrastes: estereotipos e realidades". En: A Trabe de Ouro. Publicación Galega de Pensamento Público, Tomo 3, $\mathrm{n}^{\circ} 27$, Santiago de Compostela: Sotelo Blanco, Eds., p. 85-90) (1999). "La imagen cinematográfica como soporte publicitario. Aproximación histórica al fenómeno desde Galicia". En: FERNÁNDEZ AREAL, M. (dir.) La publicidad en televisión. Pontevedra: Diputación de Pontevedra. p. 123-132. (2009). "Las tendencias de consumo del videojuego en Galicia". En: Icono14, A.2, Madrid: Asociación Científica de Comunicación y Nuevas Tecnologías. p. 463-470.

(2012) "Relaciones entre cine y publicidad. Aportaciones y reflexiones en la investigación". En: GIRONA, R. (ed.) Cinema, publicitat i turisme. Girona: Documenta Universitaria, p. 37-62.

AMORÓS PONS, A.; COMESAÑA COMESAÑA, P. (2012). "Cine y Publicidad: La imagen cinematográfica como soporte publicitario. Estudio de caso los dibujos animados". En: Ámbitos. Revista de Estudios de Ciencias Sociales y Humanidades, $\mathrm{n}^{\circ}$ 28, Montilla: Asociación de Estudios de Ciencias Sociales y Humanidades. p. 95-106.

AMORÓS PONS, A.; MARTÍNEZ COSTAS, S. (2000). O cine na publicidade. Modalidades e técnicas na creación publicitaria. Santiago de Compostela: Tórculo.

ARENS, W. (2000). Publicidad. México: McGraw Hill.

BABIN, L. A. y CARDER, S. T. (1996). "Advertising Via De Box Office: Is Product Placement Effective?" En: Journal of Promotion Management, vol. 3, n 1/2, Londres: Routledge. p. 31-51.

BAÑOS GONZÁLEZ, M. (2001). Creatividad y publicidad, Madrid: Laberinto comunicación.

BAÑOS GONZÁLEZ, M. y RODRÍGUEZ GARCÍA, T. (2005). Al filo de la verdad. Historias de la publicidad en el cine. Madrid: CIE Dossat.

BASSAT COEN, L. (1994). El libro rojo de la publicidad. Ideas que mueven montañas. Barcelona: Folio.

BENAVIDES DELGADO, J. (2003). Lenguaje Publicitario: hacia un estudio del lenguaje en los medios. Madrid: Síntesis.

BRINGUÉ SALA, X. (2001). "Publicidad infantil y estrategia persuasiva: un análisis de contenido". En: Zer, vol.6, n 10, Bilbao: Servicio Editorial Universidad País Vasco. p.107-129.

CAMARERO IZQUIERDO, C. y GARRIDO SAMANIEGO, M. J. (2004). Marketing del patrimonio cultural. Madrid: Pirámide.

COMESAÑA COMESAÑA, P. (2008). "La publicidad de emplazamiento en el cine de animación gallego. El caso de El bosque animado". En LIMA, Á. et al. (2008) (comp.). III Jornadas de Publicidade e Comunicação. Porto: Universidade Fernando Pessoa

(2010). "Gisaku, análisis educativo del uso de los dibujos animados como soporte para la inserción de publicidad". En: PERLADO LAMO DE ESPINOSA, M. \& 
JIMÉNEZ NARROS, C. (Ed.), Escenario actual de la investigación en comunicación: objetivos, métodos y desafíos. Madrid: Edipo. p. 404-410.

DAHDÁ, J. (2005). Publicidad Turística. México: Trillas.

DEL MORAL PÉREZ, M. E. (1999). "La publicidad indirecta de los dibujos animados y el consumo infantil de juguetes". En: Comunicar, $n^{\circ} 13$, Huelva: Grupo Comunicar. p. 220-224.

DEL PINO ROMERO, C. y OLIVARES DELGADO, F. (2007). “Brand placement y advertainment: integración y fusión entre la ficción audiovisual y las marcas". En: Zer, vol. 12, $\mathrm{n}^{\circ}$ 22, Bilbao: Servicio Editorial Universidad País Vasco. p. 341-367.

EGUIZÁBAL MAZA, R. (2007). Teoría de la publicidad. Madrid: Cátedra \& Signo - Imagen.

FARIAS COELHO, P. M. (2012). "Novas estrategias publicitarias: Games e advergames". En: Revista Comunicación, no 10, Vol. 1, Sevilla: Universidad de Sevilla. p. $42-51$.

FERNÁNDEZ FERNÁNDEZ, M. A.. (comp.) (2005) Rodando en Galicia 19162004. Santiago de Compostela: Consorcio Audiovisual Galicia \& Galicia Film Comisión.

FERRER RODRÍGUEZ, E (1980). La publicidad. México: Trillas.

FIGUEROA BERMÚDEZ, R. (1999). Cómo hacer publicidad. Un enfoque teórico-práctico. México: Pearson Educación.

GARCÍA UCEDA, M. (2001). Las claves de la publicidad. Madrid: ESIC.

GUTIÉRREZ GONZÁLEZ, P. P. (2002). La gestión de ventas en publicidad. Madrid: Editorial Complutense.

GONZÁLEZ MARTÍN, J. A. (1996). Teoría general de la publicidad. Madrid: FCE. HUESO MONTÓN, Á. L. (1998). El cine y el siglo XX. Barcelona: Ariel.

KLEPPNER, O. (1988). Otto Kleppner's Publicidad. México: Prencite Hall.

KONIGSBERG, I. (2004). Diccionario técnico Akal de cine. Madrid: Akal.

KOTLER, P. (1995). Dirección de Marketing. México: Prentice Hall.

LABOURE, K. (1998). The Animation Book. A complete guide to animated filmmaking-from flip-books to sound cartoons to 3-D animation. New York: Three Rivers Press.

LAW, S. y BRAUN, K A. (2000). "I'Ll Have What She'S Having: Gauging The Impact Of Product Placement On Viewers". En: Psychology and Marketing, $\mathrm{n}^{\circ}$ 12, Vol. 17, p.1059-1075.

MAGNY, J. (2005). Vocabulario de cine. Barcelona: Paidós.

MARTÍNEZ COSTA, S. (2008a). Series de ficción de producción propia en Galicia: inserción publicitaria e audiencias. Tutora: Dra. AMORÓS PONS, A., Universidade de Vigo, Memoria de Investigación de Tesis de Doctorado (Trabajo inédito). (2008b). "La publicidad de emplazamiento en la ficción televisiva. El caso de las series gallegas". En: LIMA, Á. et al. (2008) (comp.). III Jornadas de Publicidade e Comunicação. Porto: Universidade Fernando Pessoa.

MÉNDIZ NOGUERO, A. (2007). Nuevas formas publicitarias. Patrocinio, Product Placement, Publicidad en Internet. Málaga, Universidad de Málaga. 
MONTOYA VILAR, N. (2007). La influencia de la publicidad audiovisual en los niños. Estudios y métodos de investigación. Barcelona: Bosch Comunicación.

OGILVY, D. (1989). Ogilvy \& Publicidad. Barcelona: Folio.

ORTEGA MARTÍNEZ, E. (1997). La comunicación publicitaria. Madrid: Pirámide. PARÉS i MAICAS, M. (1991). Mecenatge, patrocini i comunicació. Barcelona: PPU.

PERALES BAZO, F. (Coord.) (2007). Cine y publicidad. Madrid: Fragua Comunicación.

PEREIRA DOMÍNGUEZ, C. (2005). Valores del cine de animación. Propuestas pedagógicas para padres y educadores. Barcelona: PPU.

PÉREZ RUÍZ, M.A. (1996) Fundamentos de las estructuras de la publicidad. Madrid: Síntesis.

PROPPER, F. (2007). La era de los superniños. Infancia y dibujos animados. Argentina: Alfagrama.

REDONDO BELLÓN, I. (2000). Marketing en el cine. Madrid, Pirámide-ESIC.

SALAZAR DE VELÁSQUEZ, M. y LAU, E. (2010). "Product placement en el cine: Análisis publicitario de la categoría Autos a través de diversos filmes. Medición de factores de influencia que afectan los objetivos publicitarios". En: Revista Comunicación, $\mathrm{n}^{\circ}$ 9, Vol.1, Huelva: Grupo Comunicar. p. 60-94.

SÁNCHEZ-ESCALONILLA GARCÍA-RICO, A. (2003). Diccionario de creación cinematográfica. Barcelona: Ariel Cine.

SEGARRA SAAVERDA, J. A. y PLAZA NOGUEIRA, A. (2012). "Del Product Placement al Brandplacement en la ficción audiovisual: el caso de Puleva en El Internado". En: Revista Comunicación, Nº10, Vol.1, Huelva: Grupo Comunicar. p. 1597-1609.

SELBY, A. (2009). Animación. Nuevos proyectos y procesos creativos. Barcelona: Parramón.

SELVA RUIZ, D. (2009). "El videojuego como herramienta de comunicación publicitaria: una aproximación al concepto advergaming". En: Revista Comunicación, $\mathrm{n}^{0} 7$, Vol. 1, Huelva: Grupo Comunicar. p. 141-166.

SOLOMON, M. R. y ENGLIS, B. G. (1994). "Observations: The Big Picture: Product Complementarity And Integrated Communications". En: Journal of Advertising Research, Vol. January-February, Oxfordshire: Marston. p. 57-63.

TAYLOR, R. (2004). Enciclopedia de técnicas de animación. Una guía completa de técnicas paso a paso acompañada de una notable muestra de obras terminadas. Barcelona: Alacanto.

VOLLMERS, S. y MIZERSKI, R. (1994). A Review And Investigation Into The Effectiveness Of Product Placements In Films. The 1994 Conferenceof the Academy of Advertising. Athens: American Academy of Advertising. p. 97-102.

WRIGHT, J. A. (2005). Guionización y desarrollo de la animación. Desarrollar el guión para su venta. Guipúzcoa: Elservier.

ZAPATER LÓPEZ, J. (et al.) (2004). Dibujos en el vacio. Claves del cine japonés de animación. Valencia: IVAM Documentos 11. 
Webgrafía

ANTONOPOULOU, V. (2010). "Product Placement in Film". En: Georgian National Film Center. (http://gnfc.ge/uploads/Researches\%20-\%20kvlevebi\%20/ Product\%20Placement_International.pdf) [15/06/2013]

WALTON, A. (2010). "The Evolution of Product Placement in Film". En: The Elon Journal of Undergraduate Research in Communications, $\mathrm{n}^{\circ} 1$, Vol. 1. p.70-85. (www.elon.edu/docs/eweb/academics/communications/research/07WaltonEJSpring10.pdf) [20/05/2013]

\section{Notas}

1 AUGAL (AUdiovisual GALego), proyecto subvencionado y patrocinado por el Consorcio Audiovisual de Galicia (Xunta de Galicia), durante el bienio 2010-2012 y coordinado por los profesores Anna Amorós y Miguel Anxo Fernández (Universidad de Vigo)

\section{Las autoras}

Anna Amorós Pons. Profesora Titular de Comunicación Audiovisual y Publicidad (UdV). Doctora en Ciencias de la Comunicación (UAB). Investigadora principal del Grupo I+DCS2. Guionista y Directora de Documentales. Periodista de Honor 2010-Asociación de la Prensa de Vigo. Premio Buenas Prácticas de Comunicación no sexista 2012-Associació de Dones Periodistes de Catalunya. Profesora: EINA, UAB y USC. Jefa de Comunicación Col.legi de Directors de Cinema de Catalunya. Directora de Obradoiros de Cine-AGAG. Coordinadora de AUGAL (Consorcio Audiovisual de Galicia y AGADIC). Miembro de la Comisión Asesora Libro Branco do Sector Audiovisual Galego y de la Comisión Evaluadora de Subvenciones al audiovisual (Xunta de Galicia)

Patricia Comesaña Comesaña. Doctora en Publicidad, Relaciones Públicas y Comunicación Audiovisual (UdV, 2011). Grado de Licenciatura en Publicidad y Relaciones Públicas (UdV, 2009). Título Propio de Especialista en Publicidad, Marketing y Consumo UdV, (2011) y en Dirección de Comunicación y Educación para el Consumo (UdV, 2006). Licenciada en Publicidad y Relaciones Públicas (UdV, 2005). Diplomada en Educación Primaria (UdV, 2002). Miembro investigador del Equipo I+D CS2 (UdV, 2009-2013). Profesora invitada en la UdV (2007-2008 y 2009-2010). Técnica de Soluciones Formativas Integrales (Adquiero - Grupo Femxa, Vigo). Ganadora de diversos premios de creatividad. 